\title{
Mechanical Properties of Sisal/Cattail Hybrid-Reinforced Polyester Composites
}

\author{
Silas M. Mbeche $\mathbb{D D}^{1,2}$ Paul M. Wambua, ${ }^{1}$ and David N. Githinji $\mathbb{1 D}^{1}$ \\ ${ }^{1}$ Department of Manufacturing, Industrial and Textile Engineering, School of Engineering, Moi University, Uasin Gishu County, \\ P. O. Box 3900-30100, Eldoret, Kenya \\ ${ }^{2}$ Africa Centre of Excellence II in Phytochemicals, Textiles and Renewable Energy (ACE II PTRE), Moi University, \\ Uasin Gishu County, P.O. Box 3900-30100, Eldoret, Kenya \\ Correspondence should be addressed to Silas M. Mbeche; silambeche07@gmail.com
}

Received 23 January 2020; Revised 19 February 2020; Accepted 10 March 2020; Published 30 March 2020

Academic Editor: Md Mainul Islam

Copyright (C) 2020 Silas M. Mbeche et al. This is an open access article distributed under the Creative Commons Attribution License, which permits unrestricted use, distribution, and reproduction in any medium, provided the original work is properly cited.

\begin{abstract}
Due to environmental and energy conservation concerns, a thrust towards low-cost lightweight materials has resulted in renewed interest in the development of sustainable materials that can replace nonbiodegradable and environmentally unfriendly materials in reinforced composites. In this study, mechanical properties of a hybrid composite consisting of polyester resin reinforced with a blend of sisal and cattail fibres were evaluated. The composite was fabricated using a hand lay-up technique at varying hybrid fibre weight fractions ( 5 to $25 \mathrm{wt} \%$ ) while maintaining a constant fibre blend ratio of 50/50. Composites were also prepared at a constant fibre weight fraction of $20 \%$ while varying the fibre blend ratio between 0 and $100 \%$. Fabricated composites were then characterised in terms of flexural, tensile, compressive, and impact strengths following ASTM and ISO standards. Results showed that, at a constant fibre blend ratio of 50/50, there was increase in the mechanical properties as the fibre weight fraction increased from 5 to $20 \%$. At a constant fibre weight fraction $(20 \%)$, a positive improvement in flexural, tensile, and compressive properties was registered as the fibre blend ratio varied between 0 and $75 \%$ with optimal values at a sisal/cattail ratio of $75 / 25$. The current study suggests that blending sisal and cattail fibres for production of polyester composites yields hybrid composites with enhanced mechanical properties.
\end{abstract}

\section{Introduction}

Hybrid composite materials are made up of two or more physically distinct and mechanically separable components, existing in two or more phases [1]. Normally, this aims at exploiting properties of different fibres while retaining their desirable individual characteristics in the resultant product. Since time immemorial, synthetic fibres such as carbon, glass, and aramid have dominated the composite manufacturing sector because of their low cost of production and fairly good mechanical properties [2]. However, with increasing environmental concerns, studies on the possibility of replacing synthetic fibres with natural fibres for polymer composite manufacture are on the rise $[3,4]$.

Natural plant fibres possess attractive advantages in comparison to their traditional synthetic counterparts such as glass and carbon fibres. While offering low density, high specific strength, and stiffness, natural fibres produce comparatively less toxic fumes when subjected to heat or during incineration at end life. In addition, they are renewable and biodegradable reinforcing agents, are not abrasive for processing tools, are cheap, and the feedstock for their production are usually readily available [5-7]. Unlike synthetic fibres, such ecologically friendly materials hardly impact the health of workers using them $[5,8]$. Also, their introduction in composites economises the amount of the polymeric matrix used, offering obvious economic and environmental advantages [9]. Thus, the new class of materials can be considered as a substitute to environmentally unfriendly plastic products in many nonstructural applications such as ceiling boards, walls, room partitioning, door panels, automotive industry, electronics, and food packaging [1]. 
Kenya produces approximately 25,310 tonnes of sisal fibres annually while cattail plant (Typha angustifolia) is a wild marginal weed present in most wetlands [10,11]. Sisal fibres are widely used due to their availability with each plant producing 200-250 leaves, and each leaf produces 1,000-1,200 fibre bundles [12]. On account of their better mechanical properties and abundance in most parts of the country, sisal fibres could be a promising reinforcement material in hybrid composites. The use of cattail fibres could control the invasive cattail weed and create job opportunities, as well as enhance environmental conservation.

Several researchers have investigated the effect of hybridising natural fibres such as sisal, jute, hemp, coir, and cattail on polymer matrices and how they improve the mechanical properties of the resultant polymer composites. In one of the pioneer studies, Bajwa et al. [13] evaluated a hypothesized use of cattail as a potential cellulosic raw material for the manufacture of commercial composite panels (particleboards). In their study, low-density particleboards with varying proportions of cattail and wheat straw mixed with 3\% methylene diphenyl diisocyanate resin (pMDI) had better mechanical properties than the individual fibres used singly. A blend consisting of $75 \%$ cattail and $25 \%$ wheat straw particles exhibited superior average mechanical properties for application in the particleboards. Overall the mixed blends performed better than the control $100 \%$ wheat straw or cattail in flexural stiffness and flexural strength.

In another investigation, Venkateshwaran et al. [14] reported that the mechanical performance of a hybrid composite reinforced with banana and sisal fibres in epoxybased composites resulted in an increase in the mechanical properties of the composite. To the best of our knowledge, no study in open literature has reported on the mechanical properties of hybridized sisal and cattail fibres used in the manufacture of composites. Therefore, the present study was designed to fabricate sisal-cattail fibre-reinforced polyester hybrid composite as an alternative raw material for nonstructural applications.

\section{Materials and Methods}

Unsaturated polyester resin (UPR) and methyl ethyl ketone peroxide (MEKP) were procured from Henkel Chemicals (E.A.) Ltd, Industrial area, Nairobi, Kenya. Sisal fibres, traditionally popular for making twine and ropes, were generously supplied by Lomolo Sisal Estate Ltd, Mogotio, Baringo county, Kenya. Green mature cattail plant leaves were obtained from cattail (Typha angustifolia) plants from a swamp near Moi University staff quarters, Uasin Gishu county, Eldoret, Kenya.

2.1. Preparation of Cattail Fibres and Polymer Matrix. Cattail leaves were separated from the stalk grouping at the base of the leaf followed by mechanical decortication process to extract the fibres. The fibres were then carefully dried at $80^{\circ} \mathrm{C}$ in an oven for 1 hour to remove excess moisture that would otherwise lead to poor fibre-matrix adhesion.
Mechanical properties of the neat unsaturated polyester resin (UPR, GP 1778) were density $1.23 \mathrm{~g} / \mathrm{cm}^{3}$, tensile strength 29.20 MPa, tensile modulus $2,194.70 \mathrm{MPa}$, flexural strength $70 \mathrm{MPa}$, impact strength $9 \mathrm{~kJ} / \mathrm{m}^{2}$, and an elongation at break $4.2 \%$.

2.2. Composite Fabrication. Cattail-sisal fibre-reinforced hybrid composites were prepared by simple hand lay-up technique as described by Borah et al. [1] with slight modifications. A mould measuring $310 \times 310 \times 25 \mathrm{~mm}$ was fabricated using a polished iron metal sheet from which a composite of dimensions $300 \times 300 \mathrm{~mm}$ was prepared. The mould was cleaned using acetone followed by application of the mould release agent (MR8) on the inner surfaces. The inner surfaces were then covered with aluminium foil to minimise the chances of sticking onto the mould surfaces and to provide good surface finish. The experimental design for the amount of matrix material and the reinforcements used in the polymer composite are summarized in Table 1.

Unsaturated polyester resin (UPR) and hardener (MEKP) were mixed in a ratio of $1: 0.02$ by mass as per the manufacturer's instructions and stirred thoroughly. Cattail and sisal fibres were weighed using a calibrated Mettler PM200 digital analytical balance (Marshall Scientific, Hampton, NH, USA) based on their weight percentages in the hybrid for each experimental setup and then thoroughly mixed with hands in a bowl. Hand mixing was preferred since it allowed separation of similar fibres that tended to stick together during mixing. This therefore ensured uniform dispersion of the fibres, minimizing defects in the resultant composites.

The resin was then mixed with blended fibres and stirred for 15 minutes to ensure uniform dispersion of fibres within the resin. The content was then poured into the mould and then spread gently to ensure uniform thickness of the resultant composite (Figure 1). To prevent air entrapment during fabrication, a thin plastic sheet (Velvex) was used to cover the mould and then pressed gently and uniformly using a pressure roller. The target thickness of the composite was controlled using a distant bar. This bar prevented the male mould/lid from going beyond a certain level during pressing and thus controlling its thickness. The composites were allowed to cure at ambient conditions for 6 hours under $3.27 \mathrm{kNm}^{-2}$ compressive pressure after which they were trimmed prior to mechanical tests.

2.3. Evaluation of Mechanical Properties. Composite samples $(n=5)$ for various mechanical tests were conditioned for 48 hours at ambient conditions of temperature $\left(23 \pm 2^{\circ} \mathrm{C}\right)$ and relative humidity (65\%) prior to evaluation. Tensile and compression tests were conducted using a universal testing machine (UTM-TH2730, Rycobel, Belgium) with a maximum load cell of $5 \mathrm{kN}$. The tensile and compressive properties were determined in accordance with ASTM D6382014 and ASTM D3410M-2003 standards at loading rates of $2 \mathrm{~mm} / \mathrm{min}$ and $5 \mathrm{~mm} / \mathrm{min}$, respectively.

Three-point bending property tests were conducted in accordance with the ASTM D790-2003 standard using a 
TABLe 1: Experimental design for fibre weight fraction and fibre blending (sisal/cattail).

\begin{tabular}{lcr}
\hline Test no. & Fibre weight fraction $(\%$ wt $/$ wt $)$ & Fibre blending \\
\hline 1 & 5 & $50 / 50$ \\
2 & 10 & $50 / 50$ \\
3 & 15 & $50 / 50$ \\
4 & 20 & $50 / 50$ \\
5 & 25 & $50 / 50$ \\
6 & 20 & $0 / 100$ \\
7 & 20 & $25 / 75$ \\
8 & 20 & $50 / 50$ \\
9 & 20 & $75 / 25$ \\
10 & 20 & $100 / 0$ \\
\hline
\end{tabular}
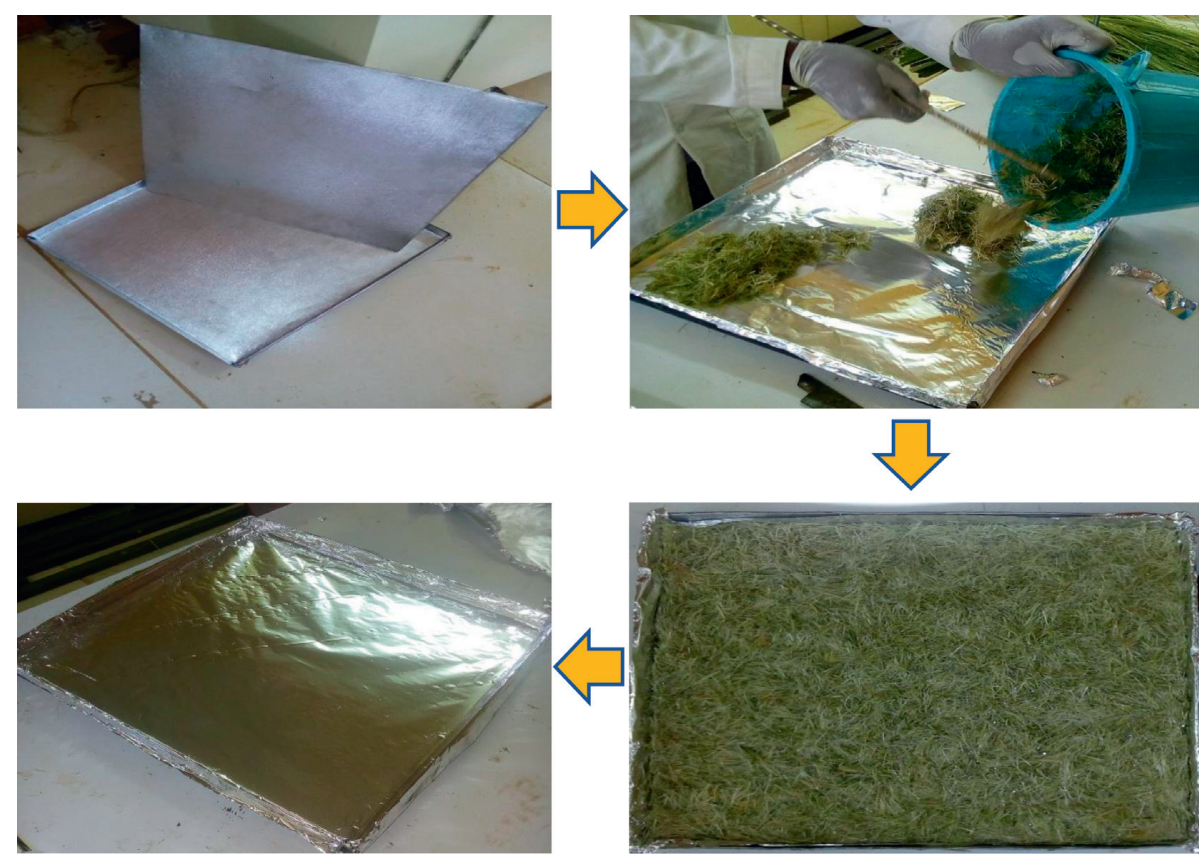

FIGURE 1: Fabrication of polyester hybrid composites.

universal material testing machine (Model UT-10, Enkay Enterprises, India) at a loading rate of $2 \mathrm{~mm} / \mathrm{min}$. Tensile, flexural, and compressive moduli were computed from the stress-strain curves. Impact strength was estimated using a Charpy impact tester (Model HLE, Enkay Enterprises, India) as per ISO 179-1:2000 standard.

2.4. Fractography Studies. Surface morphology of untreated sisal/cattail polyester hybrid composites was investigated using MSX-500Di Scopeman Digital Microscope (Herter Instruments, Barcelona, Spain).

2.5. Statistical Analysis. Analytical data were presented as means \pm standard deviations of five different measurements. One-way ANOVA was done followed by Tukey test $(p<0.05)$ using SigmaPlot software (v14, Systat Software Inc., USA). Graphical presentations were done using Microsoft Excel 2016 (Microsoft Corporation, USA) [15].

\section{Results and Discussion}

3.1. Flexural, Tensile, and Compressive Strengths of Hybrid Composites at Constant Fibre Blend Ratio. Figure 2 shows the flexural, tensile, and compressive strengths of the composites at a constant fibre blend ratio of 50/50 and varying fibre weight fractions. The flexural, tensile, and compressive strengths increased by $62.3 \%, 88.75 \%$, and $45.24 \%$ as the hybrid fibre weight fraction increased from 5 to $20 \mathrm{wt} \%$ with the maximum values of $44.92,31.40$, and $23.99 \mathrm{MPa}$, respectively (Supplementary File 1).

There were significant differences $(p<0.05)$ between the mean flexural, tensile, and compressive strengths of the composites formed by varying hybrid fibre loadings. This may be attributed to the increase in the amount of fibres as load bearing elements in the composites and their uniform distribution in the matrix as fibre loading increased to $20 \mathrm{wt} \%$. The recorded values could be due to the better fibre-matrix bond resulting from uniform distribution of the fibres and the presence of sisal fibres in the composites (Figure 3) [16, 17]. 


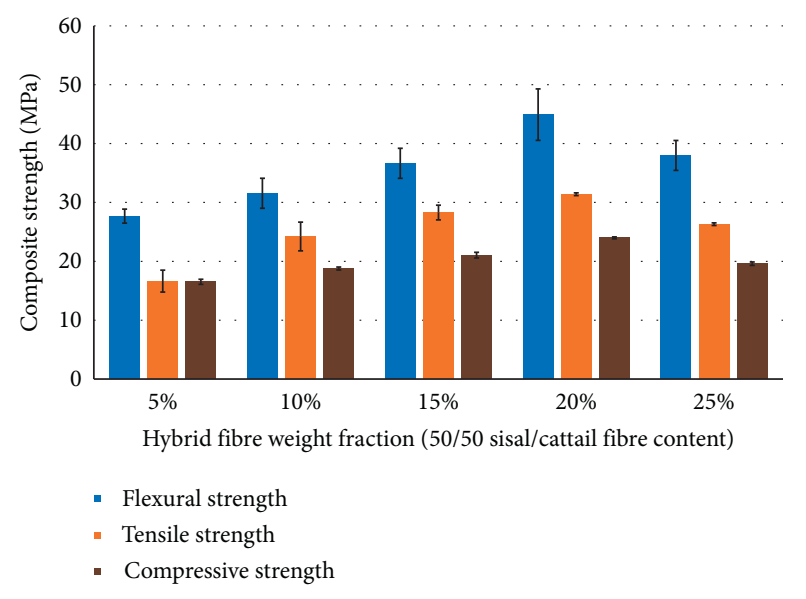

Figure 2: Flexural, tensile, and compressive strengths of hybrid composites at a constant fibre blend ratio of 50/50 and varying hybrid fibre weight fraction.

However, there was a drop in flexural, tensile, and compressive strengths by $15.43 \%, 15.08 \%$, and $20.58 \%$, respectively, as the hybrid fibre weight fraction increased from 20 to $25 \%$. This could be attributed to the possible poor interfacial bonding between the fibres and the matrix as a result of reduced fibre wetting [17-19].

Figure 4 shows a fracture micrograph of the flexural investigation test specimen for the hybrid composite at $25 \mathrm{wt} \%$ and a constant (50/50) percentage of sisal/cattail fibre in the hybrid.

This optical image shows fibre-pull-outs for both sisal and cattail fibres and thus a clear indication that there is poor stress transfer between the fibres. This is due to poor fibre wetting (fibres are clear i.e., no matrix on their surfaces) which leads to poor matrix-fibre bond and therefore resulting in higher pull-outs.

\subsection{Flexural, Tensile, and Compressive Moduli of Hybrid} Composites at Constant Fibre Blend Ratio. Figure 5 illustrates the effect of varying fibre weight fraction at a constant fibre blend ratio of 50/50 on the flexural, tensile, and compressive moduli of hybrid composites. It can be seen clearly from the results that there was an increase in flexural, tensile, and compressive moduli of the resultant hybrid composites with increase in hybrid fibre loading.

The flexural moduli of the hybrid composites increased by $45.32 \%, 25.99 \%$, and $16.08 \%$ as the hybrid fibre loading increased from 5 to 10,10 to 15 , and 15 to $20 \mathrm{wt} \%$, respectively, attaining an optimum value of $4.45 \mathrm{GPa}$. The flexural moduli recorded in this study between 5 and $20 \mathrm{wt} \%$ hybrid fibre loading are comparable to that of cattail/polyester composites reported by Rezig et al. [20] whose flexural moduli were $4.80 \mathrm{GPa}$ for sea water-treated fibres at $10.3 \mathrm{wt} \%$. Such increases in flexural moduli may be attributed to the increase in the amount of load bearing elements, fibres, and their uniform distribution within the composites which make the composites stiffer. On the contrary, tensile moduli of the resultant composites improved as the hybrid fibre loading increased from 5 to 10,10 to 15 , and 15 to $20 \mathrm{wt} \%$ by $90.53 \%$,

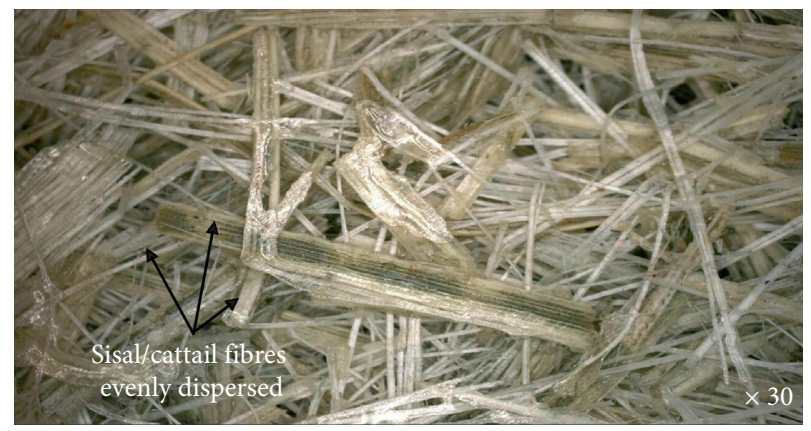

FIgURE 3: Micrograph of the sisal/cattail composite with $20 \%$ hybrid fibre weight fraction at constant fibre blend ratio.

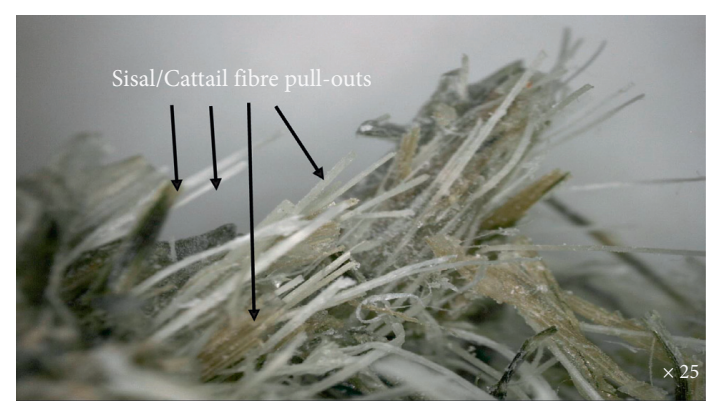

FIgURE 4: Fracture image of the hybrid composites (20 wt $\%$ at constant 50/50 sisal/cattail ratio in the blend) after flexural test.

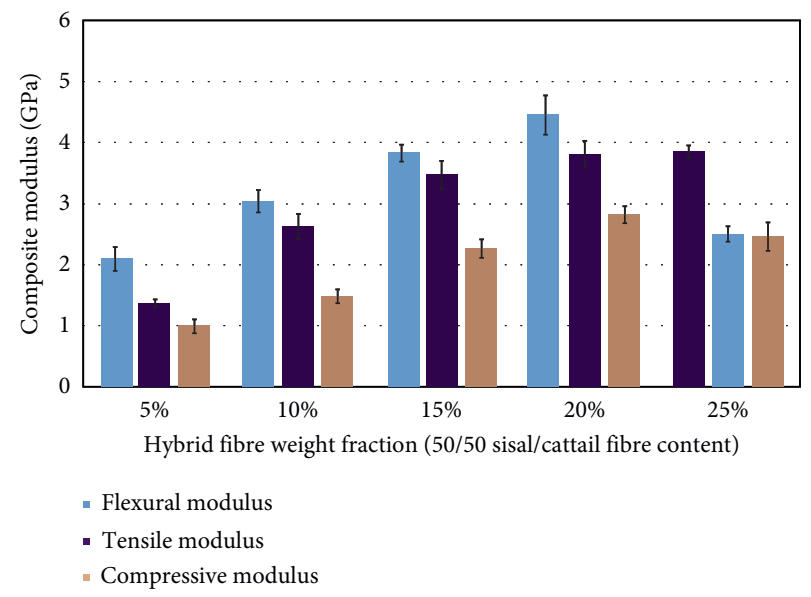

FIgUre 5: Flexural, tensile, and compressive moduli of hybrid composites at a constant fibre blend ratio of 50/50 and varying hybrid fibre weight fraction.

$32.54 \%$, and $9.68 \%$, respectively. A maximum tensile modulus of $3.81 \mathrm{GPa}$ was attained at $20 \mathrm{wt} \%$. The reported value was close to $3.09 \mathrm{GPa}$ reported for the sisal/polypropylene composite by Joseph et al. [21]. In addition, the compressive moduli of the composites increased by $49.29 \%$, $52.97 \%$, and $24.38 \%$ as the hybrid fibre loading increased from 5 to 10,10 to 15 , and 15 to $20 \mathrm{wt} \%$, respectively, with the highest compressive moduli of $2.82 \mathrm{GPa}$ recorded at $20 \mathrm{wt} \%$.

Overall, similar patterns of increase in flexural, tensile, and compressive moduli to some level with increase in 
hybrid fibre loading has been reported by preceding studies $[1,22,23]$. It is advanced that such increments could be due to the proper distribution and impregnation of load bearing elements in the matrix. In the current study, statistical analysis indicated that hybrid composites fabricated by varying hybrid weight fractions performed differently $(p<0.05)$. Further addition of fibres, i.e., $20-25 \mathrm{wt} \%$ led to a drop in flexural, tensile, and compressive moduli. This can be attributed to the nonuniform distribution of stresses due to the development of large stresses at low strains due to poor impregnation of fibres by the matrix and the possibility of air space creation at higher fibre loadings [24].

\subsection{Impact Strength of Hybrid Composites at Constant Fibre} Blend Ratio. The results of varying hybrid fibre weight fraction at a constant fibre blend ratio on the impact strength of the hybrid composites are shown in Figure 6.

There was no significant change $(p>0.05)$ in impact strength as the fibre loading increased from 5 to $10 \mathrm{wt} \%$. However, further fibre loading from 10 to $20 \mathrm{wt} \%$ resulted in a significant increase $(p<0.05)$ in impact strength, recording an optimum value of $25.61 \mathrm{~kJ} / \mathrm{m}^{2}$ at $20 \mathrm{wt} \%$ which was followed by a drop in impact strength at $20-25 \mathrm{wt} \%$. This trend was comparable to a previous study where there was no change in impact strength between 5 and $10 \mathrm{wt} \%$ followed by a moderate increase in impact strength between 10 and $20 \mathrm{wt} \%$ and a significant drop $(p<0.05)$ at $25 \mathrm{wt} \%$ [18]. The behaviour observed between 5 and $10 \mathrm{wt} \%$ may be attributed to the brittle nature of the resultant sisal/cattail hybrid composites where low fibre loadings result in less longitudinal fibres at the impacted area which subsequently results in a decrease in the resistance to crack propagation. Furthermore, there were no observed differences in the failure modes of the composites within this range. Larger serrated fracture surfaces were observed at $20 \mathrm{wt} \%$ as compared to other composites which had more less sharp fractures. This may be the reason why high impact values were reported at $20 \mathrm{wt} \%$ as serrated fractures are reported to absorb more impact energy [25]. Reduction of impact strength between 20 and $25 \mathrm{wt} \%$ may further be due to the increase in fibre-to-fibre contact resulting in fibre agglomeration which eventually leads to a drop in fibre-matrix stress transfer $[19,26]$.

3.4. Flexural, Tensile, and Compressive Strengths of Hybrid Composites at Constant Fibre Weight Fraction. Figure 7 shows the flexural, tensile, and compressive strengths of hybrid composites produced using a constant fibre weight fraction of $20 \%$ and varying fibre blend ratios.

The flexural, tensile, and compressive strengths increased by $121.83 \%, 75.46 \%$, and $62.69 \%$ as the percentage of the sisal fibre in the blend was increased from 0 to $75 \%$ to give peak values of $45.97,32.39$, and $25.43 \mathrm{MPa}$ at $75 / 25$ sisal/cattail fibre blend ratios, respectively. Analysis indicated that the flexural, tensile, and compressive strengths for each set of the composites were significantly different $(p<0.05)$ from each other. These findings were comparable with previous studies on sisal/SiC powder polyester

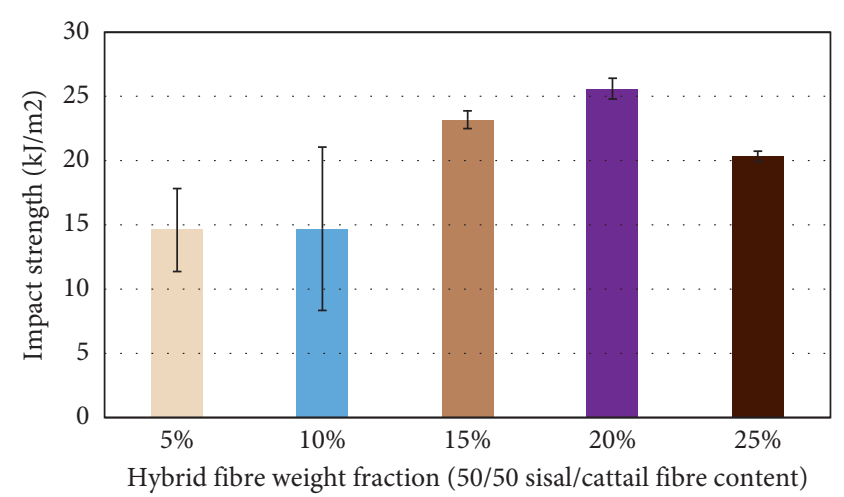

FIgURE 6: Impact strength of hybrid composites at a constant fibre blend ratio of 50/50 and varying hybrid fibre weight fraction.

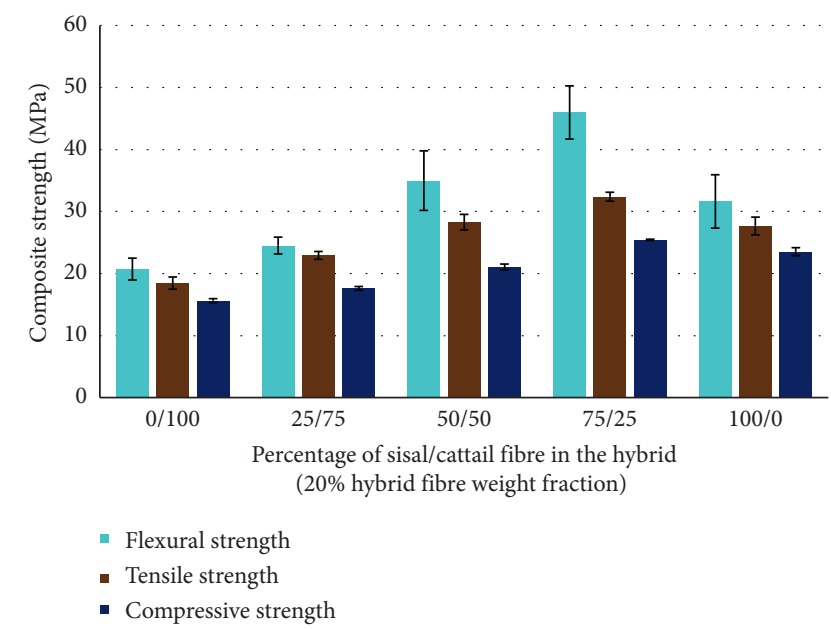

FIgURE 7: Flexural, tensile, and compressive strengths of hybrid composites at a constant fibre weight fraction of $20 \%$.

composites with a tensile strength of $28.60 \mathrm{MPa}$ [27] and banana/coconut shell powder epoxy or vinyl ester composites with flexural strengths recorded between 43.08 and 45.28 MPa [28]. It is worth noting that better mechanical properties were reported in hybrid composites than unhybridized cattail/polyester composites. This reveals a positive hybridisation effect on cattail fibres [13] and can be attributed to better dispersion of fibres in the hybrid composites compared to those fabricated from $100 \%$ cattail fibres [29].

Flexural, tensile, and compressive strengths of cattail/ polyester composites were much lower compared with sisal/ polyester composites. This trend can be explained by the fact that tensile properties of sisal fibres are higher than those of cattail fibres and thus implying that the reinforcing effect of sisal fibres in the matrix is better than that of cattail fibres (Figure 8) [17]. It was also noted that the diameter of the sisal fibre was less than that of the cattail fibre, and therefore, the surface area of the fibre exposed to the matrix is higher in sisal/polyester composites than in cattail/polyester composites $[17,29,30]$. This therefore ensures good physical interaction between the fibres and the matrix as well as better 


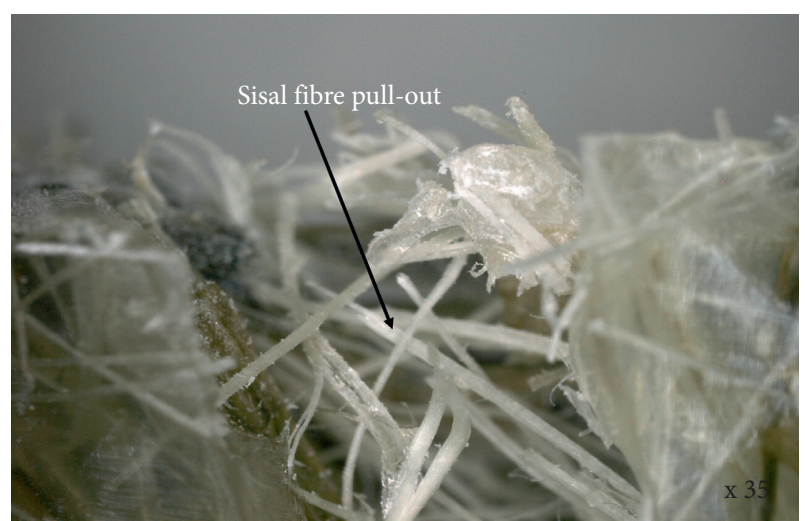

Figure 8: Micrograph showing the reinforcing effect of sisal and cattail fibres.

stress transfer between the fibres and the matrix in sisal fibrereinforced composites. This explains the trend noted in this study where flexural, tensile, and compressive strengths increased with increase in sisal fibres in the hybrid from 0 to $75 \%$ as synergism is created [29]. Furthermore, as the percentage of sisal fibre loading increased in the hybrid from 75 to $100 \%$, a drop by $31.20 \%, 14.59 \%$, and $7.41 \%$ in flexural, tensile, and compressive strengths, respectively, was observed (Supplementary File 1). The findings are consistent with a previous finding [29], and it can be attributed to fibre agglomeration caused by higher sisal fibre loading which leads to decrease in stress transfer between sisal fibres and the matrix.

\subsection{Flexural, Tensile, and Compressive Moduli of Hybrid Composites with Constant Fibre Weight Fraction.} Figure 9 illustrates the effect of varying fibre blend ratios at a constant fibre weight fraction of $20 \mathrm{wt} \%$ on the flexural, tensile, and compressive moduli of the hybrid composites.

The flexural, tensile, and compressive moduli of the hybrid composites increased as the proportion of sisal fibres in the hybrid increased from 0 to $75 \%$ with peak values of $4.26 \mathrm{GPa}, 3.82 \mathrm{GPa}$, and $2.70 \mathrm{GPa}$, respectively. Further increase in the percentage of sisal in the hybrid from $75 \%$ to $100 \%$ resulted in a significant decline in flexural, tensile, and compressive moduli of the composites by $30.16 \%, 85.78 \%$, and $73.43 \%$, respectively. This trend is consistent with previous studies that produced banana/sisal and cattail/ wheat straw polymer-reinforced hybrid composites [29, 31] and can be attributed to higher compatibility and uniform distribution of fibres in the matrix resulting in good transfer of stress between the matrix and the fibres. Decrease in flexural, tensile, and compressive moduli of the composites at higher sisal fibre loading could be attributed to fibre agglomeration and therefore poor fibre-matrix bond [32]. From these results, there was a positive hybrid effect in flexural, tensile, and compressive moduli where cattail/ polyester composite modulus was much lower compared with the sisal/polyester hybrid composites. $20 \%$ and Varying Fibre Blend Ratios. Figure 10 delineates the

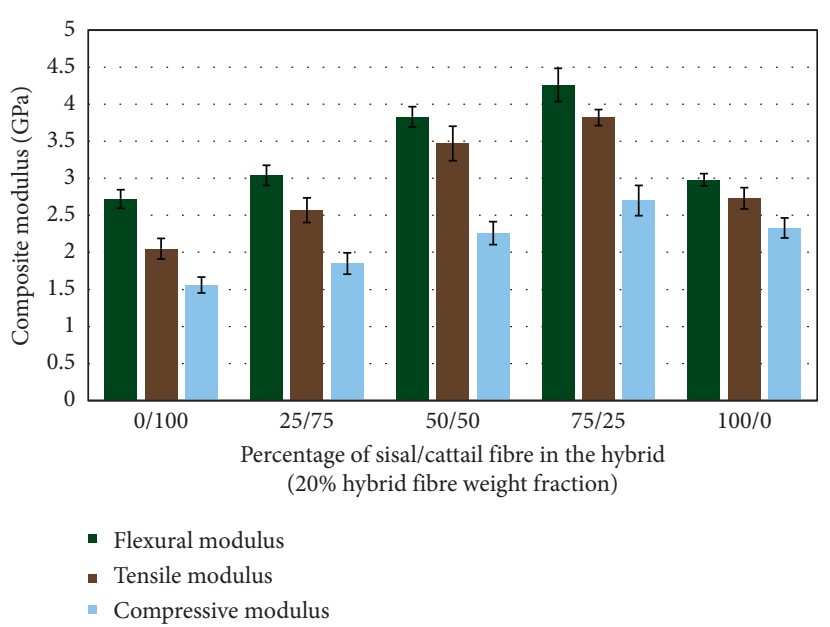

Figure 9: Flexural, tensile, and compressive moduli of hybrid composites at a constant fibre weight fraction of $20 \%$.

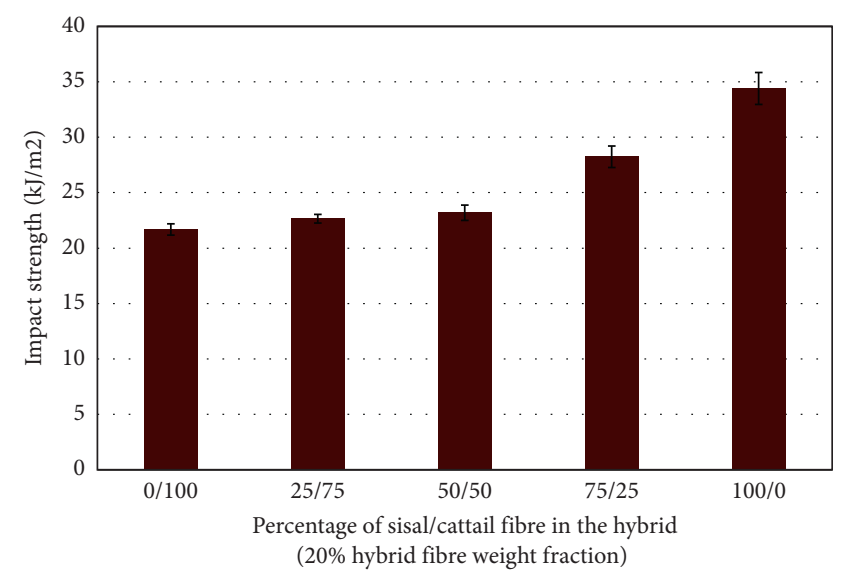

Figure 10: Impact strength of hybrid composites at a constant fibre weight fraction of $20 \mathrm{wt} \%$.

effect of varying the percentage of the sisal/cattail fibre in the hybrid at a constant hybrid fibre weight fraction of $20 \mathrm{wt} \%$ on impact strength of the composites.

The impact strength of the hybrid composites improved steadily as the percentage of the sisal fibre increased from 0 to $100 \%$ by $58.72 \%$ with a maximum value of $34.40 \mathrm{~kJ} / \mathrm{m}^{2}$ at $100 / 0 \mathrm{sisal} / \mathrm{cattail}$ ratio. This trend is concordant with previous studies in which sisal/polymer composites exhibited better impact properties $[9,16,31,33]$. The gradual increase in impact strength with increase in the sisal fibre loading could be due to its porous nature and the high microfibrillar angle of sisal fibres [29]. Therefore, impact strength increased as the sisal fibre component of the hybrid was increased, and this could have been because of the better composite fracture toughness associated with high spiral angle of sisal fibres as well as their porous nature [34]. Thus, there was a negative hybrid effect on the impact strength of the composites since sisal/polyester composites revealed better impact strength properties than cattail/polyester composites. 


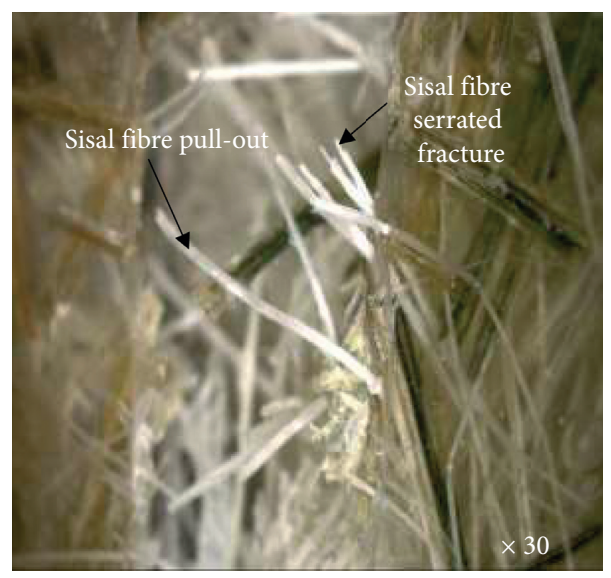

(a)

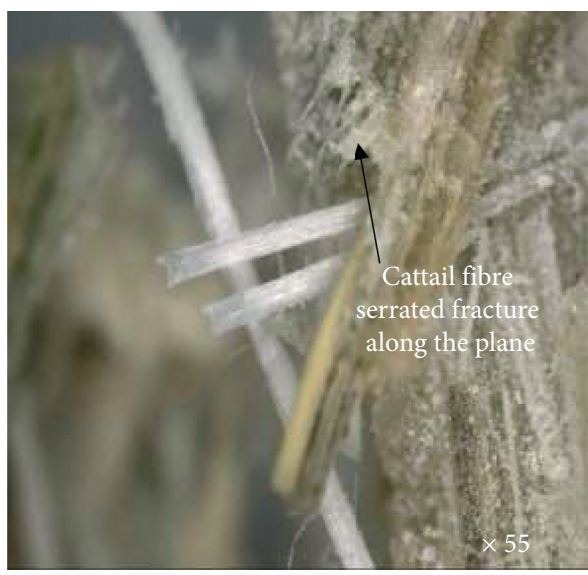

(b)

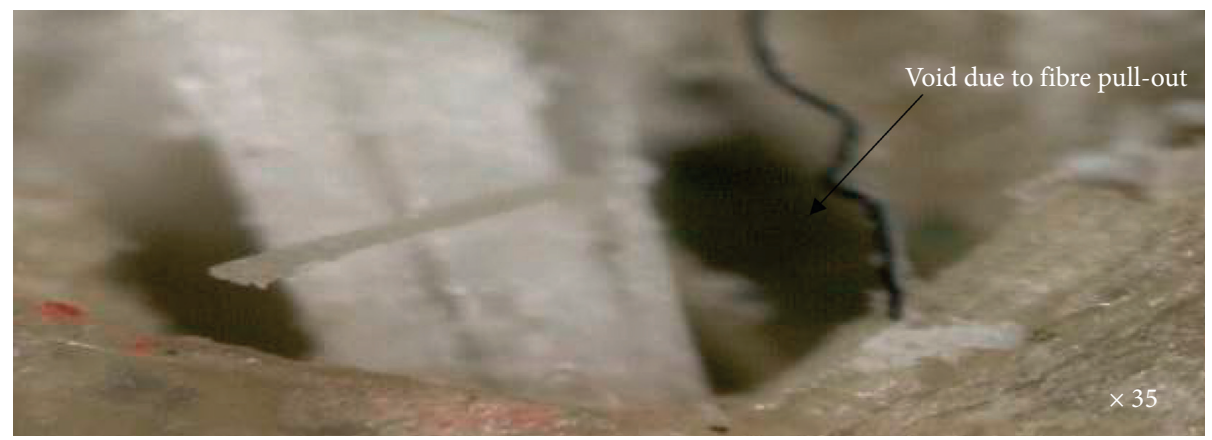

(c)

Figure 11: Hybrid composites with 20 wt $\%$ hybrid fibre weight fraction and 50/50 sisal/cattail fibre content in the hybrid after tensile test.

3.7. Surface Morphology. Figure 11 shows fracture micrographs of tensile investigation test specimens for the hybrid composite at $20 \mathrm{wt} \%$ and a constant (50/50) percentage of the sisal/cattail fibre in the hybrid. The optical images show a relatively higher percentage of fibre fracture, where more of these breakages were cattail fibres. Likewise, substantial fibrepull-outs were noted, and most of these were sisal fibres. Higher percentages of fibre breakages (cattail $>$ sisal) may be attributed to increase in fibre-to-resin ratio from 5 to $20 \mathrm{wt} \%$. Furthermore, serrated breakages of cattail fibres at the fractured edge of the composites instead of fibre-pull-outs were observed, possibly because of their low tensile strengths (due to their low cellulose content) as compared with sisal fibres $[34,35]$.

On the contrary, the serrated and twisted ends of sisal fibres observed may be attributed to good interfacial bonding and better strength of the fibres. Therefore, the failure mechanism noted here was both fibre-pull-outs (mainly sisal fibres) and fibre fracture (mainly cattail fibres and partly sisal fibres).

At $20 \mathrm{wt} \%$ hybrid fibre weight fraction and 75/25 sisal/ cattail fibre blend, a relatively high fibre-pull-out and low fibre fracture were observed (Figure 12). This could be due to the fact that there were less cattail fibres $(25 \%)$ in this fabrication as compared with sisal fibres (75\%). Therefore, the low strength of cattail fibres (due to their low cellulose content) $[34,35]$ resulted in most breakages. Since, the strength of sisal fibres was relatively good, fibre-pull-outs (of

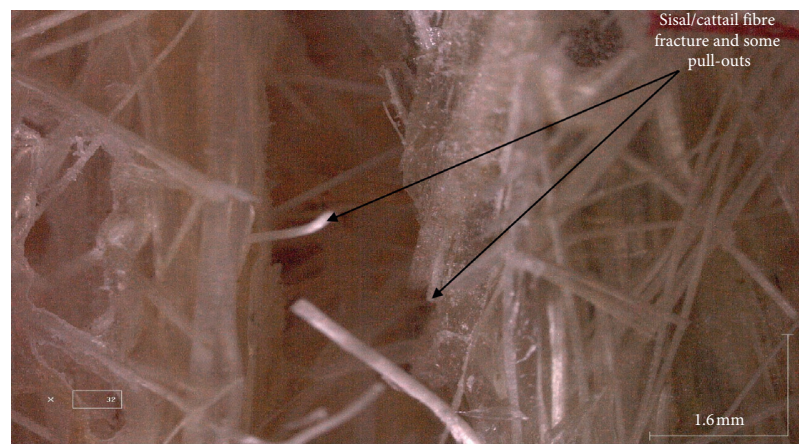

FIgURE 12: Hybrid composite at $20 \mathrm{wt} \%$ hybrid fibre weight fraction and 75/25 sisal/cattail fibre content in the hybrid after tensile test.

most sisal fibres) and breakages (of some sisal fibres) were noted. Since the percentage of sisal fibres was higher than that of cattail fibres, these composites exhibited better mechanical properties.

Thus, the current study augments previous studies which indicated that hybridization of natural fibres in polymer composites improves the mechanical properties of the resultant composites [9, 17, 31, 36, 37].

\section{Conclusion}

The current study investigated the effects of reinforcement of polyester composites with sisal/cattail fibre blends. It was 
noted that polyester hybrid composites fabricated at a constant fibre weight fraction of $20 \%$ had optimal flexural, tensile, and compressive strengths at a sisal to cattail blend ratio of $75 / 25$. Impact strength increased with increase in the sisal content of the fibre blends. Failure mechanism of sisal/ cattail fibre-reinforced polyester composites in this study was due to fibre-pull-outs (mainly sisal fibres) and fibre fracture (mainly cattail fibres and partly sisal fibres). Further research should examine the effect of chemical treatment of the fibres on the properties of the reinforced hybrid composites.

\section{Abbreviations}

ASTM: American Standard for Testing and Materials

GPa: Gigapascals ( $=10^{9}$ Pascals)

MPa: Megapascals $\left(=10^{6}\right.$ Pascals)

ISO: International Standards for Organizations

MR-8: Mould release agent

MEKP: Methyl ethyl ketone peroxide

UPR: Unsaturated polyester

wt \%: Weight percentage.

\section{Data Availability}

The data sets supporting the conclusions of this article are included within the article (and its additional files).

\section{Disclosure}

The funders of this research did not participate in the experimental design, collection of data, and had no direct influence on the decision to publish.

\section{Conflicts of Interest}

The authors declare that there are no conflicts of interest regarding the publication of this paper.

\section{Acknowledgments}

The authors are grateful to the Management of Rivatex (East Africa) Limited, Kenya, Multimedia University, Kenya, and Jomo Kenyatta University of Technology, Kenya, where different mechanical tests were done. SMM is grateful to the World Bank and the Inter-University Council of East Africa (IUCEA) for the scholarship awarded to him through the Africa Centre of Excellence II in Phytochemicals, Textiles and Renewable Energy (ACE II PTRE) at Moi University, Kenya, which led to this communication. Humble thanks to Timothy Omara, Department of Chemistry and Biochemistry, Moi University, for his assistance and expertise in the preparation, technical revision, and English proof reading of this article. This research was financially supported by the Africa Centre of Excellence II in Phytochemicals, Textiles and Renewable Energy (ACE II PTRE), Moi University (Credit no.5798-KE).

\section{Supplementary Materials}

Supplementary File 1. Mechanical properties of the polyester hybrid composites. (Supplementary Materials)

\section{References}

[1] A. Borah, D. Suchiang, K. Debnath, M. Alam, and M. Muralidhar, "Studies on design and fabrication of polymer based composite materials with fish scale reinforcement," IOSR Journal of Mechanical and Civil Engineering, vol. 2, pp. 6-11, 2016.

[2] M. Asim, M. Jawaid, N. Saba, Ramengmawii, M. Nasir, and M. T. H. Sultan, "Processing of hybrid polymer composites-a review," in Hybrid Polymer Composite Materials, pp. 1-12, Woodhead Publishing, Cambridge, UK, 2017.

[3] K. L. Pickering, M. G. A. Efendy, and T. M. Le, "A review of recent developments in natural fibre composites and their mechanical performance," Composites Part A: Applied Science and Manufacturing, vol. 83, pp. 98-112, 2016.

[4] O. Bongomin, G. G. Ocen, E. N. Onyondi, A. Musinguzi, and T. Omara, "Exponential disruptive technologies and the required skills of industry 4.0," Journal of Engineering, vol. 2020, Article ID 4280156, 17 pages, 2020.

[5] K. G. Satyanarayana, G. G. C. Arizaga, and F. Wypych, "Biodegradable composites based on lignocellulosic fibers-an overview," Progress in Polymer Science, vol. 34, no. 9, pp. 982-1021, 2009.

[6] L. Liu, J. Yu, L. Cheng, and W. Qu, "Mechanical properties of poly(butylene succinate) (PBS) biocomposites reinforced with surface modified jute fibre," Composites Part A: Applied Science and Manufacturing, vol. 40, no. 5, pp. 669-674, 2009.

[7] W. N. Gilfillan, D. M. T. Nguyen, P. A. Sopade, and W. O. S. Doherty, "Preparation and characterisation of composites from starch and sugar cane fibre," Industrial Crops and Products, vol. 40, pp. 45-54, 2012.

[8] E. Frollini and A. Castellan, "Phenolic resins and composites," in Wiley Encyclopedia of Composites, pp. 2059-2068, John Wiley \& Sons, Hoboken, NJ, USA, 2nd edition, 2012.

[9] E. Frollini, N. Bartolucci, L. Sisti, and A. Celli, "Poly(butylene succinate) reinforced with different lignocellulosic fibers," Industrial Crops and Products, vol. 45, pp. 160-169, 2013.

[10] B. Colbers, S. Cornelis, E. Geraets et al., A Feasibility Study on the Usage of Cattail (Typha spp.) for the Production of Insulation Materials and Bio-Adhesives, Wageningen University and Research Centre, Wageningen, Netherlands, 2017.

[11] Committee on Commodity Problems, Joint Meeting of the Thirty-Ninth Session of the Intergovernmental Group on Hard Fibres and the Forty-First Session of the Intergovernmental Group on Jute, Kenaf and Allied Fibres, Committee on Commodity Problems, Tanga, United Republic of Tanzania, 2017.

[12] P. S. Mukherjee and K. G. Satyanarayana, "Structure and properties of some vegetable fibres," Journal of Materials Science, vol. 19, no. 12, pp. 3925-3934, 1984.

[13] D. S. Bajwa, E. D. Sitz, S. G. Bajwa, and A. R. Barnick, "Evaluation of cattail (Typha spp.) for manufacturing composite panels," Industrial Crops and Products, vol. 75, pp. 195-199, 2015.

[14] N. Venkateshwaran, A. ElayaPerumal, A. Alavudeen, and M. Thiruchitrambalam, "Mechanical and water absorption behaviour of banana/sisal reinforced hybrid composites," Materials \& Design, vol. 32, no. 7, pp. 4017-4021, 2011. 
[15] T. Omara, S. Karungi, R. Kalukusu et al., "Mercuric pollution of surface water, superficial sediments, Nile tilapia (Oreochromis nilotica Linnaeus 1758 [Cichlidae]) and yams (Dioscorea alata) in auriferous areas of Namukombe stream, Syanyonja, Busia, Uganda," PeerJ, vol. 7, no. e7919, pp. 1-33, 2019.

[16] P. Sivasubramanian, M. Thiruchitrambalam, and R. Shyamaraj, "Hybridization of natural fiber composites on mechanical properties," International Journal of Engineering Science Research, pp. 1-9, 2013.

[17] S. M. Mbeche and T. Omara, "Effects of alkali treatment on the mechanical and thermal properties of sisal/cattail polyester commingled composites," PeerJ Material Science Chemistry, vol. 2, no. 5, pp. 1-19, 2020.

[18] P. Vimalanathan, N. Venkateshwaran, and V. Santhanam, "Mechanical, dynamic mechanical, and thermal analysis of Shorea robusta-dispersed polyester composite," International Journal of Polymer Analysis and Characterization, vol. 21, no. 4, pp. 314-326, 2016.

[19] S. Rizal, Ikramullah, D. A. Gopakumar, S. Thalib, S. Huzni, and H. P. S. Abdul Khalil, "Interfacial compatibility evaluation on the fiber treatment in the Typha fiber reinforced epoxy composites and their effect on the chemical and mechanical properties," Polymers, vol. 10, p. 1316, 2018.

[20] S. Rezig, K. Foued, B. M. Yosser et al., "Flexural properties of Typha natural fiber-reinforced polyester composites," Fibers and Polymers, vol. 16, pp. 2451-2457, 2015.

[21] P. Joseph, K. Joseph, and S. Thomas, "Effect of processing variables on the mechanical properties of sisal-fiber-reinforced polypropylene composites," Composites Science and Technology, vol. 59, no. 11, pp. 1625-1640, 1999.

[22] H. T. Ondiek, J. Ngetha, Keraita, and J. B. Byiringiro, "Investigating the effect of fiber concentration and fiber size on mechanical properties of rice husk fiber reinforced polyester composites," International Journal of Composite Materials, vol. 8, pp. 105-115, 2018.

[23] D. O. Bichang'a and H. R. Ayub, "Effect of fibre weight fraction on mechanical properties of woven sisal fabric reinforced epoxy composites," International Journal of Engineering and Science Invention, vol. 6, pp. 72-75, 2017.

[24] N. S. V. Gupta, Akash, K. V. S. Rao, and D. S. Arun, "Fabrication and evaluation of mechanical properties of alkaline treated sisal/hemp fiber reinforced hybrid composite," IOP Conference Series on Material Sciences Engineering, vol. 149, p. 012093, 2016.

[25] P. Wambua, J. Ivens, and I. Verpoest, "Natural fibres: can they replace glass in fibre reinforced plastics?" Composites Science and Technology, vol. 63, no. 9, pp. 1259-1264, 2003.

[26] C. Girisha, Sanjeevamurthy, and G. Rangasrinivas, "Tensile properties of natural fiber-reinforced epoxy-hybrid composites," International Journal of Modern Engineering Research, vol. 2, no. 2, pp. 471-474, 2012.

[27] M. S. Teja, M. Ramana, D. Sriramulu, and C. J. Rao, "Experimental investigation of mechanical and thermal properties of sisal fibre reinforced composite and effect of SiC filler material," Materials Science and Engineering, vol. 149, 2016.

[28] J. Santhosh, N. Balanarasimman, R. Chandrasekar, and S. Raja, "Study of properties of banana fiber reinforced composites," International Journal of Engineering Science Research Technology, vol. 3, pp. 144-150, 2014.

[29] M. Idicula, K. Joseph, and S. Thomas, "Mechanical performance of short banana/sisal hybrid fiber reinforced polyester composites," Journal of Reinforced Plastics and Composites, vol. 29, no. 1, pp. 12-29, 2010.
[30] S. Rezig, M. Jaouadi, and S. Msahli, "Study of structure and properties of Tunisian Typha leaf fibers," International Journal of Engineering Research \& Technology, vol. 3, no. 3, pp. 539-546, 2014.

[31] K. V. S. Akash, N. S. V. Rao, A. Gupta, and D. S. Kumar, "Mechanical properties of sisal/coir fiber reinforced hybrid composites fabricated by cold pressing method," IOP Conference Series on Materials Science and Engineering, vol. 149, 2016.

[32] H. P. S. A. Khalil, M. Jawaid, A. Hassan, M. T. Paridah, and A. Zaidon, Composites and their Applications, Intech Open Limited, London, UK, 2012.

[33] M. Ramesh, K. Palanikumar, and K. H. Reddy, "Mechanical property evaluation of sisal-jute-glass fiber reinforced polyester composites," Composites Part B: Engineering, vol. 48, pp. 1-9, 2013.

[34] A. Bledzki and J. Gassan, "Composites reinforced with cellulose based fibres," Progress in Polymer Science, vol. 24, no. 2, pp. 221-274, 1999.

[35] S. M. Mortazavi and M. K. Moghadam, "Introduction of a new vegetable fiber for textile application," Journal of Applied Polymer Science, vol. 113, pp. 3307-3312, 2009.

[36] P. Kongkaew, S. Namsak, and W. Pharanat, "Comparative investigation on physical and mechanical properties of water hyacinth and cattail fiber reinforced epoxy hybrid composites," IOP Conference Series: Journal of Physics, vol. 1144, pp. 1-5, 2018.

[37] O. D. Samuel, S. Agbo, and T. A. Adekanye, "Assessing mechanical properties of natural fibre reinforced composites for engineering applications," Journal of Journal of Minerals and Materials Characterization and Engineering, vol. 11, no. 8, pp. 785-789, 2012. 